\title{
СОСТАВ ФАУНЫ И БИОТОПИЧЕСКОЕ РАСПРЕДЕЛЕНИЕ ДОЛГОНОСИКООБРАЗНЫХ ЖУКОВ (COLEOPTERA, CURCULIONOIDEA) ЗАПОВЕДНИКА «ШАЙТАН-ТАУ»
}

\author{
FAUNA COMPOSITION AND BIOTOPIC DISTRIBUTION OF WEEVILS \\ (COLEOPTERA, CURCULIONOIDEA) OF THE SHAYTAN-TAU RESERVE
}

\author{
С.В. Дедюхин ${ }^{1}$, Р.В. Филимонов² \\ S.V. Dedyukhin ${ }^{1}$, R.V. Filimonov ${ }^{2}$ \\ ${ }^{1}$ Удмуртский государственный университет, \\ Россия, 426034, г. Ижевск, ул. Университетская, 1/1 \\ 2 Ленинградский зоопарк, \\ Россия, 197198, Санкт-Петербург, Александровский парк, 1 \\ ${ }^{1}$ Udmurt State University, \\ 1/1 Universitetskaya St, Izhevsk, 426034, Russia \\ ${ }^{2}$ Leningrad Zoo, \\ 1 Alexandrovskiy park, Sankt-Petersburg, 197198, Russia \\ E-mail: ded@udsu.ru; rostvf@yandex.ru
}

\begin{abstract}
Аннотация
В статье впервые приведены сведения о видовом составе и дана общая характеристика фауны жуков надсемейства Curculionoidea государственного заповедника «Шайтан-Тау», расположенного на юговосточной оконечности дубравной лесостепи низкогорий Южного Урала. В результате исследований было выявлено 288 видов долгоносикообразных жуков из 6 семейств. Из них 79 видов впервые указываются для фауны Оренбургской области, а западнопалеарктический вид Magdalis caucasica (Tournier, 1872) впервые обнаружен на Урале. Фауну долгоносиков заповедника отличают неоднородная зоогеографическая структура и контрастное сочетание низкогорных лесостепных, петрофитностепных и пойменных комплексов, каждый из которых характеризуется высоким видовым богатством и содержит группы видов (неморальных, бореальных, степных), находящихся здесь на границах своих ареалов. В частности, это виды, тесно связанные с дубом (Attelabus nitens, Gasterocercus depressirostris, Curculio glandium, C. venosus, Archarius pyrrhoceras, Orchestes hortorum). Данные, представленные в статье, подтверждают обоснованность проведения по хребту Шайтан-Тау ряда биогеографических границ и подчеркивают важное значение заповедника для сохранения своеобразных природных комплексов Уральской горной страны.
\end{abstract}

Abstract

In the article, information on the species composition is presented for the first time, and the general characteristics of the fauna of beetles of the Curculionoidea superfamily of the Shaitan-Tau State Reserve, located at the southeastern end of the oak forest-steppe of the lowlands of the Southern Urals, is carried out. As a result of research, 288 species of weevils from 6 families were identified. Of these, 79 species are first reported for the fauna of the Orenburg Region, and the West Palaearctic species Magdalis caucasica (Tournier, 1872) was first found in the Urals. The fauna of the reserve's weevils is distinguished by a heterogeneous zoogeographic structure and a contrasting combination of low-mountain forest-steppe, petrophyte-steppe and floodplain complexes, each of which is characterized by high species richness and contains groups of species (nemoral, boreal, steppe) located here on the borders of their ranges. In particular, these are species closely related to oak (Attelabus nitens, Gasterocercus depressirostris, Curculio glandium, C. venosus, Archarius pyrrhoceras, Orchestes hortorum). The data presented in the article confirm the validity of drawing a number of biogeographic boundaries along the Shaitan-Tau ridge and emphasize the importance of the reserve for the preservation of the peculiar natural complexes of the Ural mountainous country.

Ключевые слова: долгоносикообразные жуки, Curculionoidea, заповедник «Шайтан-Тау», фауна, биотопические комплексы.

Keywords: weevils, Curculionoidea, reserve «Shaitan-Tau», fauna, biotopic complexes. 


\section{Введение}

Государственный природный заповедник «Шайтан-Тау» расположен на севере Кувандыкского района Оренбургской области (рис. 1). Территория заповедника охватывает правобережную часть долины реки Сакмары, восточный склон и приводораздельную часть Сакмаро-Куруильского междуречья. Данная территория находится на южной оконечности лесных и лесостепных южноуральских низкогорий, основной массив которых занимает юго-восточную часть Башкирии [Чибилев, 2015]. Главная природная черта хребта Шайтан-Тау - нахождение здесь на юго-восточном пределе распространения европейских широколиственных лесов и дубравной лесостепи, сходной с лесостепью Русской равнины, но имеющей некоторые особенности в составе, структуре и распределении сообществ, определяющиеся горным характером местности [Калмыкова и др., 2016].

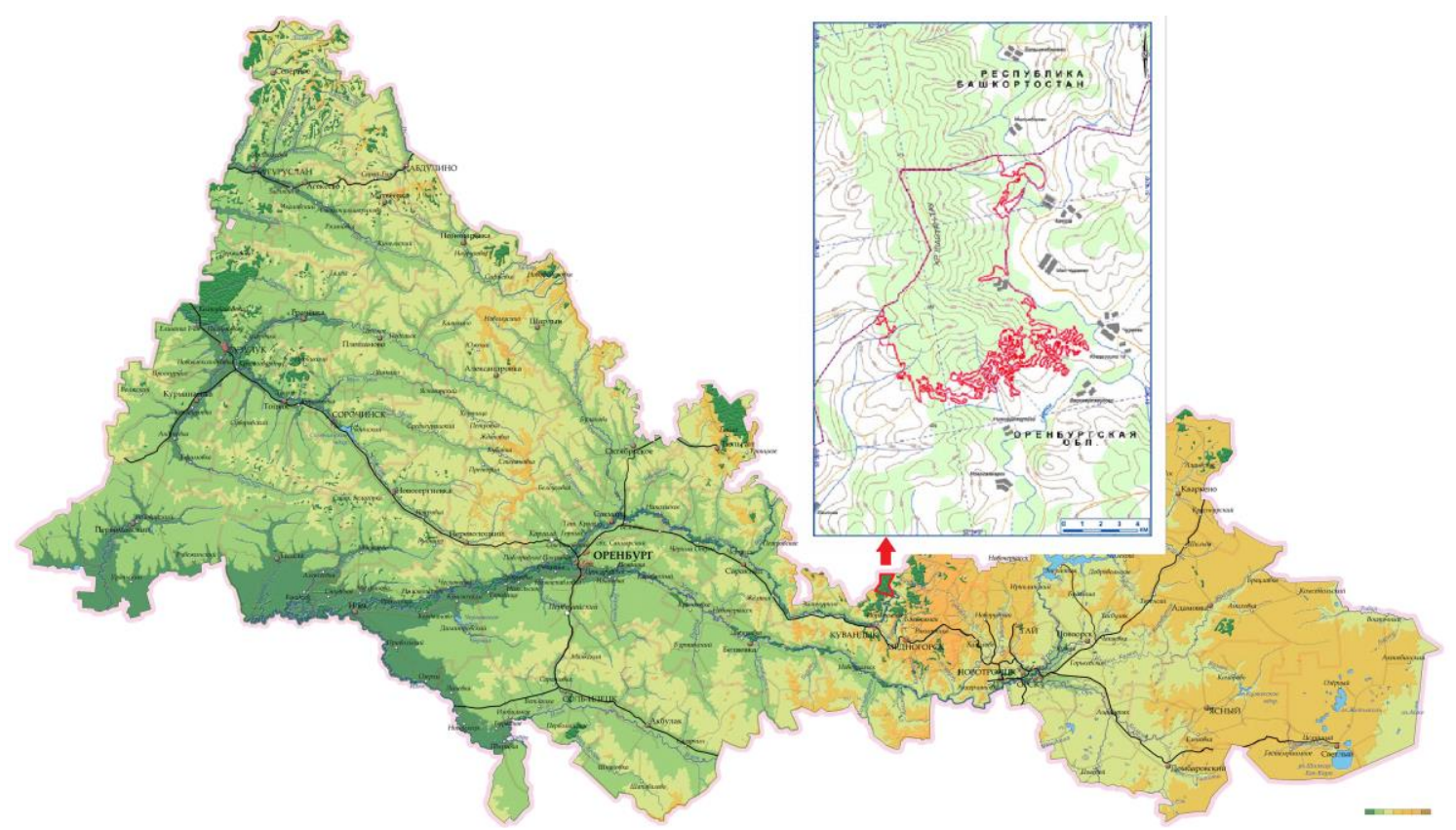

Рис. 1. Местоположение в Оренбургской области и карта-схема заповедника «Шайтан-Тау»

Fig. 1. Location in the Orenburg region and a schematic map of the Shaitan-Tau reserve

«Шайтан-Тау» - один из самых молодых заповедников России (создан в 2014 г.). Площадь заповедника составляет 6576 га. Еще около 7000 га, включающие в основном лесостепные участки с преобладанием луговых степей, предлагается включить в охранную зону заповедника, но это предложение до сих пор не реализовано на практике [Калмыкова и др., 2016]. Координаты крайних точек заповедника: северная точка -

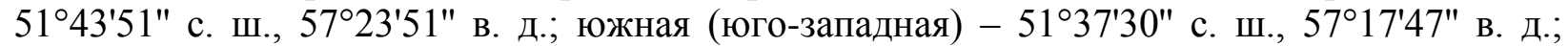

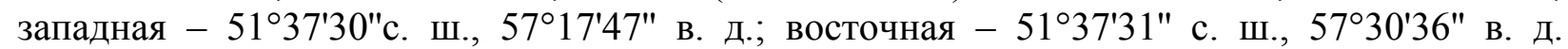
Северная и северо-западная граница участка совпадает с границей Оренбургской области и Республики Башкортостан. Восточная часть границы лесного массива совпадает с подошвой коренного прибрежного склона, затем захватывая пойменные леса до уреза воды р. Сакмары, в некоторых местах огибая используемые земли сельхозназначения и базы отдыха [Чибилев, 2015] (см. рис.1).

По геологическому составу на хребте Шайтан-Тау господствуют силурийские отложения, представленные кремнистыми сланцами и подушечными лавами основного состава, образовавшимися в результате вулканических излияний на дне силурийского моря. Среди интрузивных магматических пород в заповеднике преобладают гипербазиты, на поверхности преобразованные в серпентиниты, которые на территории заповедника, как и в других районах Урала, нередко обрамляются кремнистыми или основными 
вулканогенными породами силура. В целом для поверхностных отложений Шайтан-Тау (как и для всего Урала) характерна триада темноокрашенных (от зеленовато-серых до почти черных) горных пород (серпентиниты, основные вулканиты и кремнистые сланцы офиолитовый комплекс). В заповеднике преобладают породы этого комплекса, степень их обнаженности очень высокая, и эта территория может считаться одним из эталонов проявления офиолитов [Чибилев, 2015].

Рельеф заповедника представляет собой контрастное приречное низкогорье, которое входит в Уральскую горноскладчатую страну. Самая высокая точка заповедника в верховьях ручья Кара-Суры на хребте Шайтан-Тау имеет отметку 577,8 м, а самая низкая (урез воды в р. Сакмаре у бывшего с. Нижнее Утягулово) - 208 м. Перепады высот происходят на небольших расстояниях, склоны нередко сменяются обрывами, холмы и гряды часто увенчаны скалистыми останцами [Чибилев, 2015].

В целом на территории заповедника можно выделить три различных по происхождению яруса рельефа. Верхний - это реликты пенеплена (остатки верхнего плато), средний - это лабиринт приречного мелкосопочника, и нижний - равнины пойм наиболее значительных рек [Чибилев, 2015].

На Шайтан-Тау располагается один из наиболее южных участков горной лесостепи Южного Урал [Зоны и типы поясности растительности ..., 1999]. Растительный покров заповедника представляет собой сочетание восточно-европейских широколиственных дубовых и кленово-липовых лесов в мозаичном сочетании с различными вариантами луговых, злаково-разнотравных и каменистых степей [Романова, 2011]. Дубовые и смешанные широколиственные леса располагаются в средней и нижней части склонов, поднимаясь в виде сужающихся языков по распадкам. В узких долинах рек и ручьёв произрастают мезофильные и гигромезофильные леса с ольхой черной в комплексе с кустарниковыми и луговыми сообществами. Каменистые вершины сыртов, верхние части южных склонов и плоские водораздельные вершины (плато) обезлеснены и остепнены [Романова, 2011; Чибилев, 2015] (рис. 2-5).

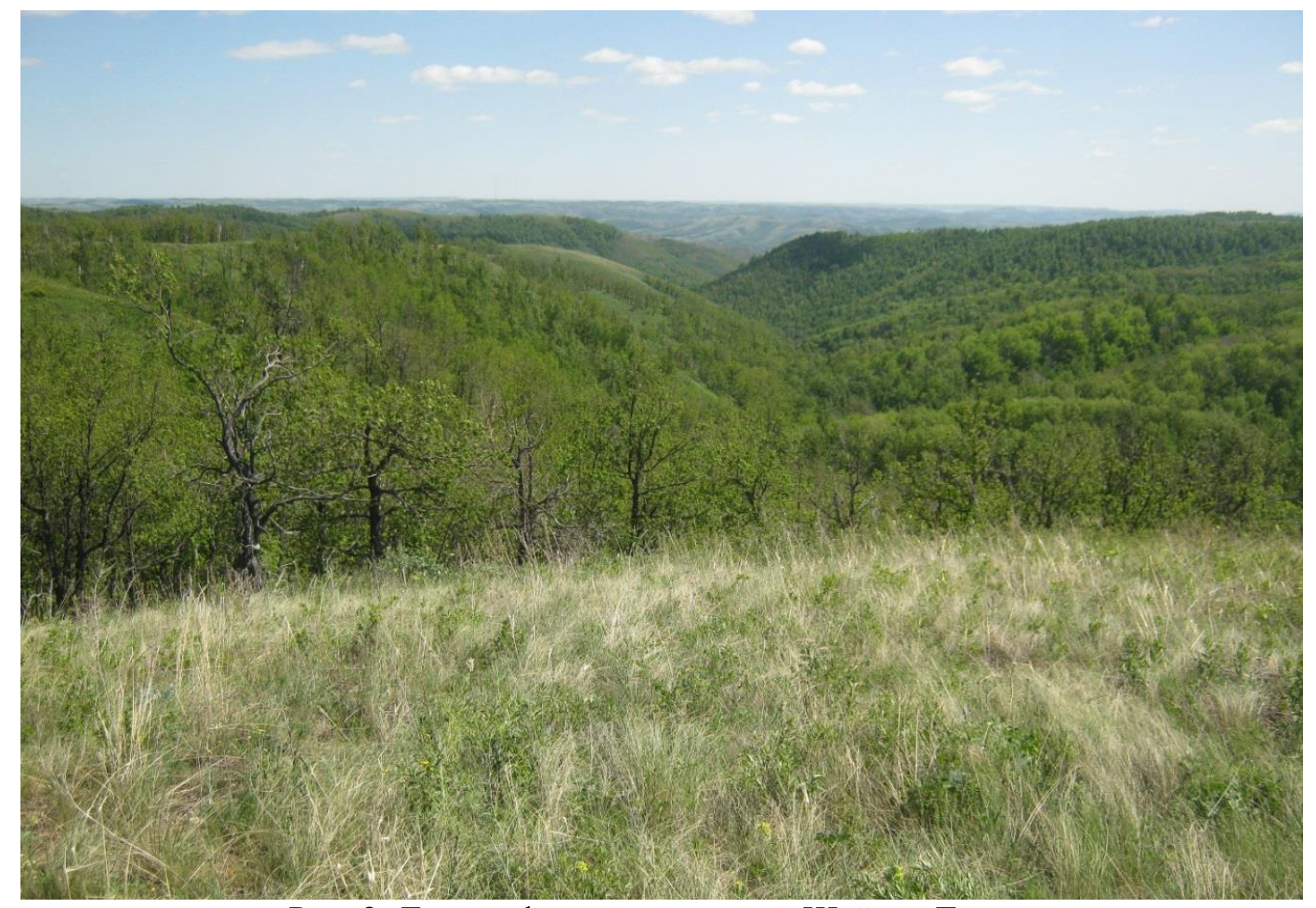

Рис. 2. Ландшафты заповедника «Шайтан-Тау»-

ковыльная степь на плато и дубравы в горной ложбине

Fig. 2. Landscapes of the Shaitan-Tau reserve - feather grass steppe on a plateau and oak forests in amountain hollow) 


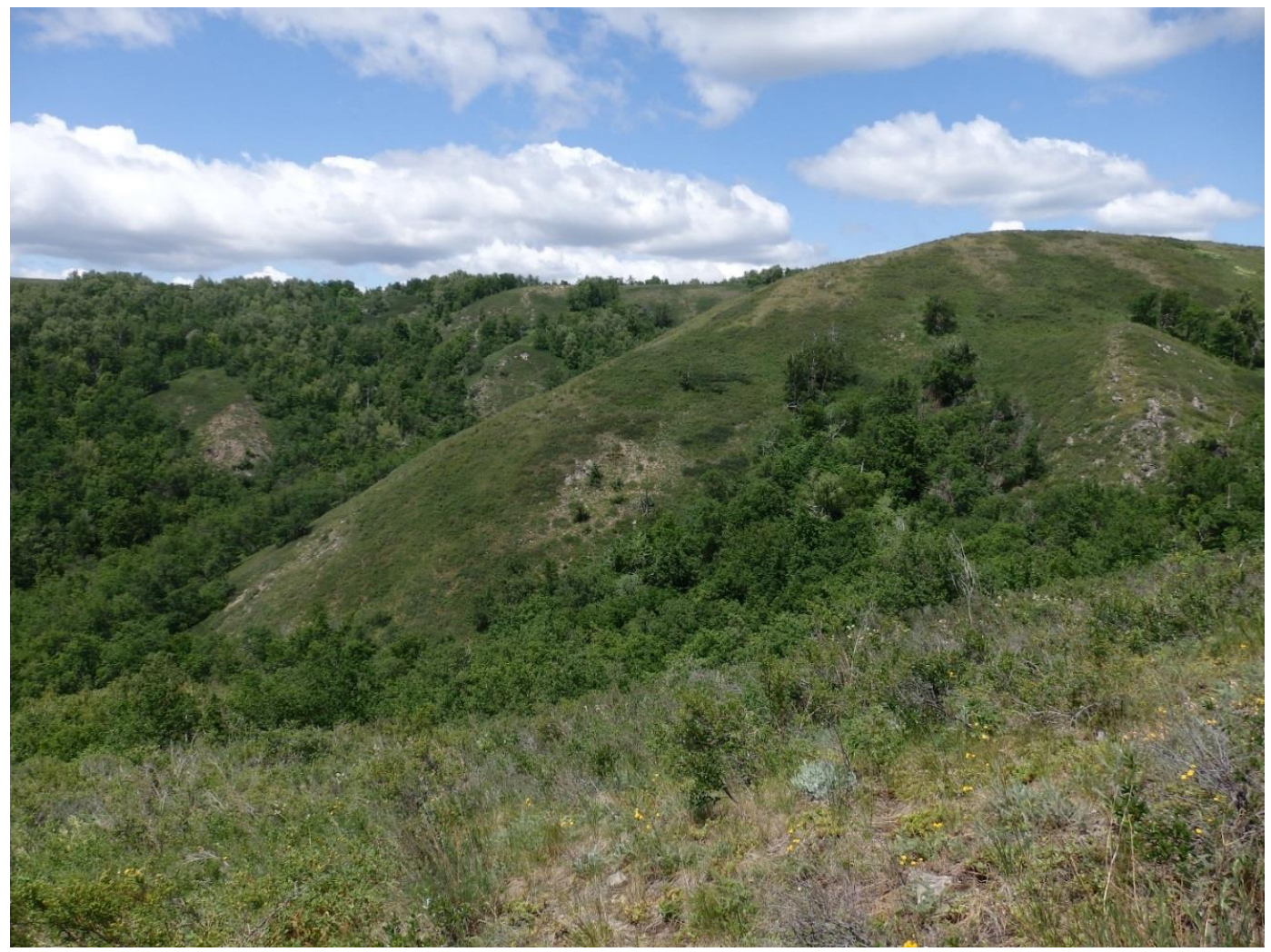

Рис. 3. Ландшафты заповедника «Шайтан-Тау» - горная дубравная лесостепь

Fig. 3. Landscapes of the Shaitan-Tau reserve - mountain oak forest-steppe

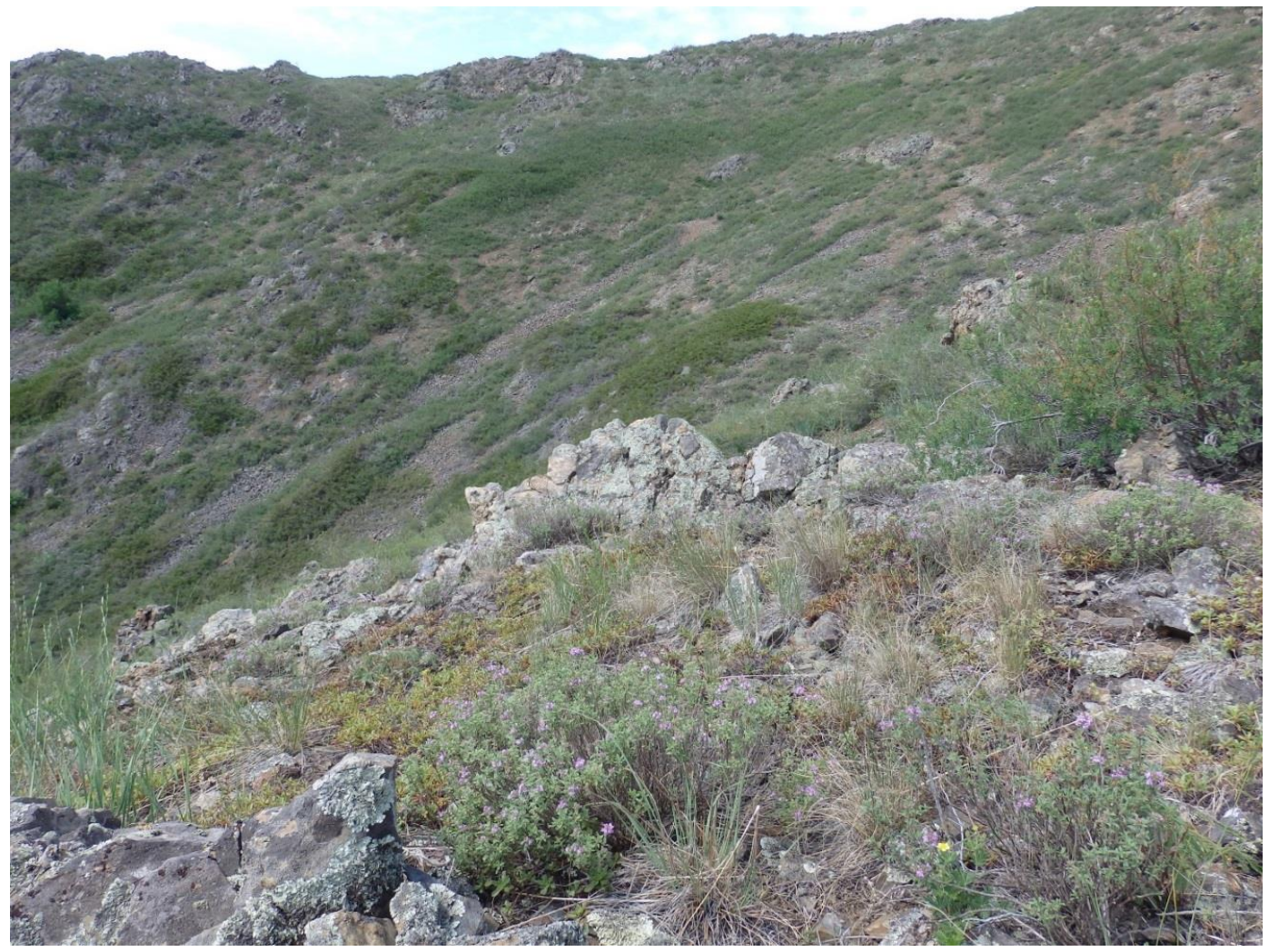

Рис. 4. Ландшафты заповедника «Шайтан-Тау» - каменистые степи горы Караман

Fig. 4. Landscapes of the Shaitan-Tau reserve - rocky steppes of Karaman mountains 


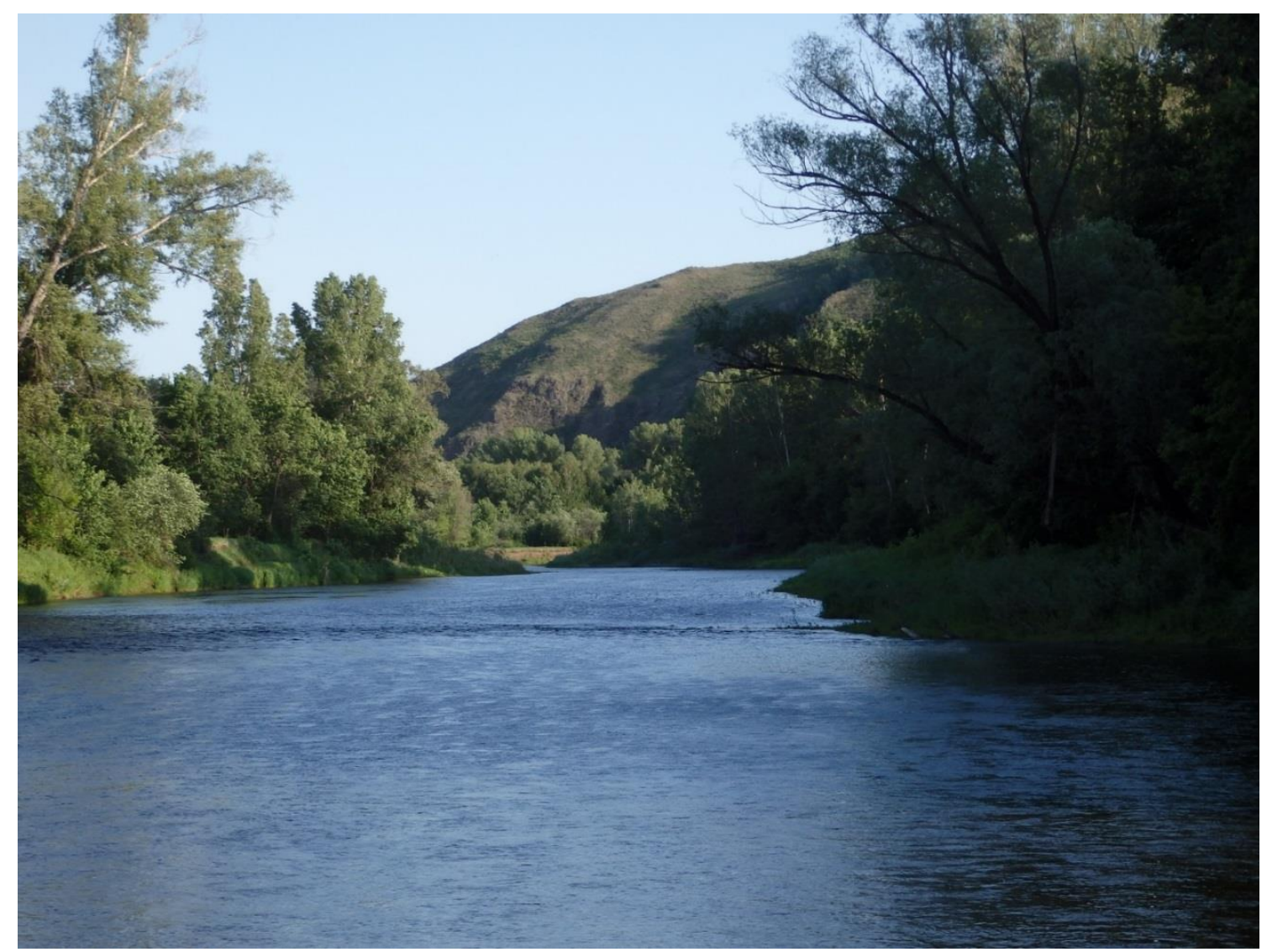

Рис. 5. Ландшафты заповедника «Шайтан-Тау» - уремные леса по берегам р. Сакмары Fig. 5. Landscapes of the Shaitan-Tau reserve - riparian forests along the banks of the river. Sakmars

Доминирующее положение в водораздельных лесах занимают формации богатых во флористическом отношении ксеромезофильных дубовых лесов. Они обычно соседствуют с липовыми лесами, зарослями степных кустарников и степями. В сложении древесного яруса этих сообществ принимают участие дуб черешчатый (Quercus robur), береза повислая (Betula pendula), липа мелколистная (Tilia cordata), клен остролистный (Acer platanoides), осина (Populus tremula), вяз шершавый (Ulmus glabra). В типичном варианте доминирует дуб. В составе кустарникового яруса обычны вишня кустарниковая (Cerasus fruticosa), карагана кустарниковая (Caragana frutex), ракитник русский (Chamaecytisus ruthenicus), шиповник (Rosa glabrifolia). В травяном ярусе наблюдается совместное присутствие лесных, луговых, опушечных и степных видов, что характерно для светлых, разреженных дубовых лесов лесостепной зоны. В лесах и на их опушках произрастают и уральские лесные эндемики - Knautia tatarica, Lathyrus litvinovii. К восточной границе хребта примыкает облесенная пойма p. Сакмара, для которой характерны ивняки и тополевники, а по ручьям - притокам Сакмары - ленточные черноольшаники с доминированием Alnus glutinosa [Романова, 2011; Шаповалов, 2011; Чибилев, 2015].

В сложении растительного покрова хребта Шайтан-Тау значительное место занимают степи, характерной чертой которых является обилие петрофитных видов. Петрофитноразнотравные степи характерны для вершин и скалистных склонов с выходами коренных пород. Травяной покров разрежен, общее проективное покрытие составляет лишь 5-20\%. В качестве доминантов обычно выступают Astragalus helmii, Hedysarum razoumovianum, Echinops ruthenicus, Artemisia salsoloides. К группе наиболее постоянных видов для петрофитных степей относятся следующие: Ephedra distachya, Elytrigia pruinifera, Helictotrichon desertorum, Orostachys spinosa, Sedum hybridum, Thymus 
mugodzharicus, Allium globosum, Clausia aprica, Silene baschkirorum, Dianthus uralensis, D. acicularis, Onosma guberlinensis, Centaurea marschalliana, Astragalus karelinianus, Aster alpinus, Tanacetum kittaryanum. Местами формируются горные кустарниковые степи и заросли степных кустарников, в состав которых входят Caragana frutex, Amygdalus nana, Cerasus fruticosa, Spiraea hipericifolia, S. crenata, Cotoneaster melanocarpus. На выходах горных пород часты заросли можжевельника казацкого (Juniperus sabina) [Романова, 2011; Кин и др., 2016].

Флору заповедника отличает значительное видовое богатство и черты своеобразия. В результате предварительных флористических исследований при проектировании заповедника было выявлено 229 видов растений [Романова, 2011], однако реальное флористическое богатство, вероятно, значительно выше, так как на хребте Шайтан-Тау в целом (в первую очередь в его башкирской части) было выявлено 450 видов сосудистых растений из 70 семейств [Мулдашев, Галеева, 1994]. По хребту Шайтан-Тау проходит юго-восточная граница распространения дубовых лесов, и вместе с тем, это предел распространения ряда бореальных и неморальных видов флоры, в том числе и восточная граница ареала Quercus robur [Чибилев, 2015; Кин и др., 2016].

Своеобразие флоры Шайтан-Тау заключается в произрастании здесь на границе распространения ряда неморальных, бореальных и сухостепных видов, а также в большом числе реликтовых и эндемичных видов, которые сконцентрированы преимущественно в ассоциациях горных степей [Романова, 2011; Калмыкова и др., 2016].

Несмотря на то, что сборы насекомых на данной территории осуществлялись с начала 90-х годов, публикаций, посвященных инвентаризации каких-либо групп энтомофауны данного участка, очень мало. В основном приводятся лишь самые общие данные о наиболее характерных видах энтомофауны, в разные годы, полученные В.А. Немковым [Чибилев, 2015]. Исключение составляют работы А.М. Шаповалова [2011, 2012], в которых довольно подробно описана фауна жуков-усачей (Cerambycidae) данного участка (выявлено 70 видов и еще около 10 на прилегающих территориях). Отмечается при этом, что местная локальная фауна усачей отличается наибольшим видовым богатством по сравнению с другими хорошо изученными локальными фаунами Оренбургской области. Интересные находки видов из ряда других семейств жуков в окрестностях с. Малое Чураево указаны в статье А.М. Шаповалова с соавторами [2011], в том числе двух видов долгоносиков - Pseudocleonus dauricus (Gebl.) и Adosomus roridus (Pall.).

В статье первого автора [Дедюхин, 2019а], посвященной предварительной инвентаризации жуков-листоедов заповедных участков Оренбуржья (заповедник «Шайтан-Тау» и пять кластеров Оренбургского заповедника) для Шайтан-Тау указано 93 вида этого семейства. В другой работе [Дедюхин, 2019б], проведено обобщение данных по известному к тому времени видовому богатству листоедов и долгоносикообразных заповедных участков Оренбуржья (в Шайтан-Тау к началу 2019 г. был зарегистрирован 191 вид Curulionoidea). В качестве особенностей фауны жуковфитофагов заповедника «Шайтан-Тау» отмечено сочетание неморальных видов на восточном пределе распространения (в частности, комплекс видов, тесно связанных с дубом), группы реликтовых сибирских видов, а также видов бореального происхождения на южных границах ареалов с указанием отдельных примеров. Однако список видов надсемейства Curculionoidea фауны заповедника до настоящего времени не публиковался. 


\section{Материал и методы исследования}

В основу статьи положены оригинальные сборы авторов в разные годы. Сборы первого автора осуществлялись в рамках комплексных эколого-фаунистических исследований жуков-фитофагов заповедных участков Оренбуржья в течение четырех последовательных экспедиций (июнь 2017, май 2018, июнь 2019 и июнь 2020 гг.). Сборы второго автора осуществлены в период проектирования заповедника (июнь 2009, июнь 2010, май 2011 гг.). Кроме того, собственные сборы (включая необработанные на ватных матрасиках), осуществленные в этот же период, любезно предоставил А.М. Шаповалов. Небольшой, но интересный материал, собранный методом почвенных банок-ловушек в начале мая 2018 г., предоставил С.Ю. Есюнин.

Всего было собрано и обработано свыше 2300 экземпляров жуков-долгоносиков. Сборы авторов статьи проведены стандартными методами (энтомологическое кошение, сбор с кормовых растений) с охватом всех основных биотопов, представленных в заповеднике и на большей части его территории. Материал в основном хранится в личных коллекциях авторов, по некоторым видам часть экземпляров передана в коллекцию Зоологического института РАН (г. Санкт-Петербург).

Определение видов жуков-фитофагов проводилось с использованием набора определителей и ревизий [Бей-Биенко, 1965; Dieckmann, 1972, 1974, 1977, 1983, 1988; Исаев, 2007; Забалуев, 2020], а также путем сравнения с материалами из фондовой коллекции ЗИН РАН. Проверку определений ряда видов осуществил Б.А. Коротяев (ЗИН РАН).

Номенклатура видов принята по последней версии «Каталога долгоносикообразных жуков Палеарктики» [Alonso-Zarazaga et al., 2020] ${ }^{1}$. По этому источнику в основном приняты номенклатура и объем семейств и подсемейств, но подсемейства Baridinae и Ceutorhynchinae рассматриваются нами в традиционном понимании, а не в ранге надтриб в составе подсемейства Conoderinae.

Все фотографии, представленные в статье, оригинальные (автор С.В. Дедюхин) и сделаны на территории заповедника «Шайтан-Тау».

\section{Результаты и их обсуждение}

Всего к настоящему времени на территории заповедника «Шайтан-Тау» зарегистрировано 288 видов долгоносикообразных жуков из 6 семейств (см. таблицу). Из них 79 видов впервые отмечены для фауны Оренбургской области. Хотя состав фауны заповедника еще не может считаться выявленными полностью (по нашим оценкам на данной территории возможно обитание еще не менее 70 видов надсемейства), даже установленное число показывает высокое видовое богатство куркулионоидофауны заповедника. На сходных с ним по площади участках Оренбургского заповедника, расположенных в пределах степной зоны Оренбуржья, отмечено не более 230-250 видов, а в наиболее засушливых (Ащисайская степь) - немногим более 100 видов. Все это подчеркивает чрезвычайную видовую насыщенность комплексов жуков-долгоносиков в лесостепных ландшафтах, что было отмечено нами ранее и для равнинных территорий востока Русской равнины [Дедюхин, 2016а].

${ }^{1}$ Исключение составляет Larinus iaceae volgensis Becker, 1864, в каталоге рассматриваемый как синоним Larinus iaceae (Fabricius, 1775). Но по нашим данным [Дедюхин, 2014], это особая форма, имеющая заметные морфологические и экологические отличия от типичной формы Larinus iaceae. 
Таблица

Table

Состав фауны и распределение по основным типам биотопов долгоносикообразных жуков

(Curculionoidea) заповедника «Шайтан-Тау»

Fauna composition and distribution of weevils (Curculionoidea)

by the main biotopes of the Shaitan-Tau reserve

\begin{tabular}{|c|c|c|c|c|c|}
\hline \multirow[b]{2}{*}{ Таксоны } & \multicolumn{5}{|c|}{ Типы биотопов } \\
\hline & 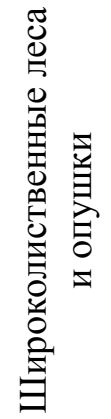 & 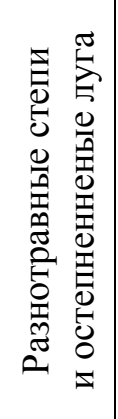 & 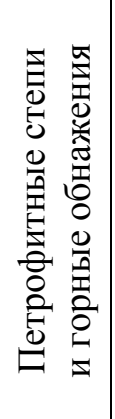 & 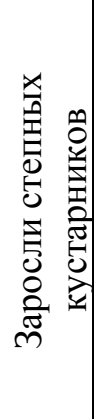 & 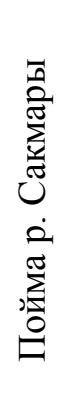 \\
\hline 1 & 2 & 3 & 4 & 5 & 6 \\
\hline \multicolumn{6}{|l|}{ Cem. Anthribidae } \\
\hline \multicolumn{6}{|l|}{ Подсем. Anthribinae } \\
\hline Anthribus scapularis Gebler, 1833 & + & & & + & \\
\hline A. fasciatus Forster, 1770 & + & & & & \\
\hline Platystomos albinus (Linnaeus, 1758) & + & & & & + \\
\hline Tropideres albirostris (Schaller, 1783) & + & & & & \\
\hline Platyrhinus resinosus (Scopoli, 1763) & + & & & & + \\
\hline Dissoleucas niveirostris (Fabricius, 1798) & + & & & & + \\
\hline \multicolumn{6}{|l|}{ Подсем. Urodontinae } \\
\hline Bruchela orientalis (Strejcek, 1982) & & + & + & & \\
\hline B. schusteri (Schilsky, 1912)* & & & + & & \\
\hline B. concolor (Fåhraeus, 1839)* & & + & + & & \\
\hline B. musculus K. Daniel \& J. Daniel, 1903* & & + & + & & \\
\hline \multicolumn{6}{|l|}{ Cем. Attelabidae } \\
\hline \multicolumn{6}{|l|}{ Подсем. Rhynchitinae } \\
\hline Deporaus betulae (Linnaeus, 1758) & + & & & & \\
\hline Temnocerus subglaber (Desbrochers des Loges, 1897) & & & & + & + \\
\hline T. coeruleus (Fabricius, 1798) & + & & & & \\
\hline T. nanus (Paykull, 1792) & & & & & + \\
\hline Neocoenorrhinus germanicus (Herbst, 1797) & + & + & & + & + \\
\hline N. minutus (Herbst, 1797)* & & & & + & \\
\hline N. pauxillus (Germar, 1824) & + & & & + & \\
\hline Tatianaerhynchites aequatus (Linnaeus, 1767) & + & & & + & \\
\hline Mecorhis aethiops (Bach, 1854) & & + & & & + \\
\hline M. ungarica (Herbst, 1783) & & & & + & \\
\hline Involvulus pubescens (Fabricius, 1775) & & + & & & + \\
\hline Rhynchites auratus (Scopoli, 1763) & + & & & + & \\
\hline Byctiscus betulae (Linnaeus, 1758) & + & & & & + \\
\hline B. populi (Linnaeus, 1758) & + & & & + & + \\
\hline \multicolumn{6}{|l|}{ Подсем. Attelabinae } \\
\hline Attelabus nitens (Scopoli, 1763) & + & & & & \\
\hline Compsapoderus erythropterus (Gmelin, 1790)* & & + & & & + \\
\hline Apoderus coryli (Linnaeus, 1758) & + & & & & \\
\hline
\end{tabular}


Продолжение таблицы

Continuation of Table

\begin{tabular}{|c|c|c|c|c|c|}
\hline 1 & 2 & 3 & 4 & 5 & 6 \\
\hline \multicolumn{6}{|l|}{ Сем. Brentidae } \\
\hline \multicolumn{6}{|l|}{ Подсем. Apioninae } \\
\hline Omphalapion hookerorum (Kirby, 1808)* & & + & & & \\
\hline Diplapion sareptanum (Desbrochers des Loges, 1867) & & & + & & \\
\hline D. detritum (Mulsant \& Rey, 1859) & & + & & & + \\
\hline Ceratapion onopordi (Kirby, 1808) & & + & + & & + \\
\hline C. ?secundum (Ter-Minasian, 1972) & & + & & & \\
\hline Aspidapion radiolus (Marsham, 1802)* & & + & & & + \\
\hline A. $\operatorname{soror}(\mathrm{Rey}, 1895) *$ & & + & & & \\
\hline Melanapion minimum (Herbst, 1797) & + & & & & + \\
\hline Squamapion elongatum (Germar, 1817) & & + & + & & \\
\hline S. samarense (Faust, 1891) & & + & & & \\
\hline Taeniapion urticarium (Herbst, 1784) & + & & & & + \\
\hline Exapion difficile (Herbst, 1797)* & & + & & + & + \\
\hline E. corniculatum (Germar, 1817) & & & & + & \\
\hline Pseudoprotapion ergenense (Becker, 1864) & & & + & & \\
\hline Protapion fulvipes (Geoffroy, 1785) & & + & & & + \\
\hline P. ruficrus (Germar, 1817) & & + & & & \\
\hline P. assimile (Kirby, 1808) & + & + & & & \\
\hline P. apricans (Herbst, 1797)* & & + & & & \\
\hline Aizobius sedi (Germar, 1818) & & & + & & \\
\hline Pseudostenapion simum (Germar, 1817)* & & + & + & & \\
\hline P. brevirostre (Herbst, 1797) & & + & + & & + \\
\hline Perapion violaceum (Kirby, 1808) & & & + & & + \\
\hline P. curtirostre (Germar, 1817) & & & + & & + \\
\hline P. oblongum (Gyllenhal, 1839) & & & + & & + \\
\hline P. connexum (Schilsky, 1902) & & & & & + \\
\hline Apion cruentatum Walton, 1844 & & & & & + \\
\hline Loborhynchapion amethystinum (Miller, 1857) & & & + & & \\
\hline Catapion seniculus (Kirby, 1808) & & + & & & + \\
\hline Betulapion simile (Kirby, 1811)* & + & & & & \\
\hline Cyanapion columbinum (Germar, 1817) & + & + & & & \\
\hline C. alcyoneum (Germar, 1817) & & + & & & \\
\hline C. platalea (Germar, 1817) & + & & & & \\
\hline C. gnarum (Faust, 1890)* & + & + & & & \\
\hline Eutrichapion viciae (Paykull, 1800) & + & + & & + & + \\
\hline E. ervi (Kirby, 1808)* & + & + & & & + \\
\hline E. melancholicum (Wencker, 1864)* & + & & & & \\
\hline Подсем. Nanophyinae & & & & & \\
\hline Nanophyes globiformis Kiesenwetter, $1864^{*}$ & & & & & + \\
\hline N. marmoratus (Goeze, 1777) & & & & & + \\
\hline Nanomimus ?hemisphaericus (Olivier, 1807)* & & & & & + \\
\hline Cем. Curculionidae & & & & & \\
\hline Подсем. Dryophthorinae & & & & & \\
\hline Sphenophorus abbreviatus (Fabricius, 1787) & & & & & + \\
\hline Подсем. Brachycerinae & & & & & \\
\hline Tanysphyrus lemnae (Paykull, 1792)* & & & & & + \\
\hline Подсем. Mesoptiliinae & & & & & \\
\hline Magdalis ruficornis (Linnaeus, 1758) & + & & & & \\
\hline M. serricollis Reitter, $1895^{*}$ & + & & & + & \\
\hline
\end{tabular}


Продолжение таблицы

Continuation of Table

\begin{tabular}{|c|c|c|c|c|c|}
\hline 1 & 2 & 3 & 4 & 5 & 6 \\
\hline M. armigera (Geoffroy, 1785) & + & & & & \\
\hline M. carbonaria (Linnaeus, 1758)* & + & & & & \\
\hline M. caucasica (Tournier, 1872)* & + & & & & \\
\hline M. nitida (Gyllenhal, 1827) & + & & & & \\
\hline \multicolumn{6}{|l|}{ Подсем. Molytinae } \\
\hline Hylobius transversovittatus (Goeze, 1777) & & & & & + \\
\hline Liparus coronatus (Goeze, 1777) & & + & & & \\
\hline Lepyrus palustris (Scopoli, 1763) & & & & & + \\
\hline Gasterocercus depressirostris (Fabricius, 1792) & + & & & & \\
\hline \multicolumn{6}{|l|}{ Подсем. Cossoninae } \\
\hline Phloeophagus turbatus Schoenherr, 1845* & + & & & & \\
\hline \multicolumn{6}{|l|}{ Подсем. Lixinae } \\
\hline Conorhynchus nigrivittis (Pallas, 1781) & & & + & & \\
\hline Cleonis pigra (Scopoli, 1763) & & + & & & + \\
\hline Cyphocleonus dealbatus (Gmelin, 1790) & & + & + & & + \\
\hline C. adumbratus (Gebler, 1833) & & & & & + \\
\hline Adosomus roridus (Pallas, 1781) & & + & + & & \\
\hline Mecaspis alternans (Hellwig, 1795) & & + & + & & \\
\hline Pseudocleonus dauricus (Gebler, 1829) & & & + & & \\
\hline P. cinereus (Schrank, 1781) & & & + & & \\
\hline Pachycerus segnis (Germar, 1824) & & + & & & \\
\hline Bothynoderes affinis (Schrank, 1781) & & + & & & \\
\hline Rhinocyllus conicus (Froelich, 1792) & & + & + & & \\
\hline Larinus vulpes (Olivier, 1807) & & & + & & \\
\hline L. sturnus (Schaller, 1783) & & + & & & + \\
\hline L. carlinae (Olivier, 1807) & & + & & & \\
\hline L. turbinatus Gyllenhal, 1835 & & + & + & & + \\
\hline L. iaceae volgensis Becker, 1864 & & & + & & \\
\hline L. centaurii (Olivier, 1807) & & + & + & & \\
\hline L. serratulae Becker, 1864 & & + & + & & \\
\hline Lixus cylindrus (Fabricius, 1781) & & + & & & \\
\hline L. iridis Olivier, 1807 & + & & & & + \\
\hline L. myagri Olivier, 1807 & & & & & + \\
\hline L. scolopax Boheman, $1835^{*}$ & & & + & & \\
\hline L. filiformis (Fabricius, 1781) & & + & + & & \\
\hline L. cardui Olivier, 1807 & & + & & & \\
\hline L. bardanae (Fabricius, 1787) & + & + & & & + \\
\hline L. fasciculatus Boheman, 1835 & & + & & & + \\
\hline L. pulverulentus (Scopoli, 1763)* & & + & & & \\
\hline \multicolumn{6}{|l|}{ Подсем. Baridinae } \\
\hline Baris artemisiae (Panzer, 1794) & & + & & & + \\
\hline Malvaevora timida (Rossi, 1792) & & + & & & \\
\hline Aulacobaris janthina (Boheman, 1836) & & + & & & + \\
\hline Limnobaris dolorosa (Goeze, 1777) & & & & & + \\
\hline \multicolumn{6}{|l|}{ Подсем. Ceutorhynchinae } \\
\hline Neophytobius granatus (Gyllenhal, 1835) & & & & & + \\
\hline Rhinoncus perpendicularis (Reich, 1797) & & & & & + \\
\hline Rh. leucostigma (Marsham, 1802) & & + & & & + \\
\hline Rh. incospectus (Herbst, 1795) & & & & & + \\
\hline Rutidosoma graminosum (Gistel, 1857) & + & & & & \\
\hline
\end{tabular}


Продолжение таблицы

Continuation of Table

\begin{tabular}{|c|c|c|c|c|c|}
\hline 1 & 2 & 3 & 4 & 5 & 6 \\
\hline Tapinotus sellatus (Fabricius, 1794)* & + & & & & + \\
\hline Ceutorhynchus roberti Gyllenhal, 1837* & + & & & & + \\
\hline C. puncticollis Boheman, $1845^{*}$ & & & & & + \\
\hline C. inaffectatus Gyllenhal, 1837 & & & & & + \\
\hline C. interjectus Schultze, $1903^{*}$ & + & & & & + \\
\hline C. rapae Gyllenhal, $1837^{*}$ & + & + & & & + \\
\hline C. fabrilis Faust, 1887 & & & + & & \\
\hline C. griseus C. N. F. Brisout de Barneville, $1869^{*}$ & & + & + & & \\
\hline C. granulicollis C. G. Thomson, 1865 & & + & + & & \\
\hline C. kaszabi Korotyaev, 1980 & & + & + & + & \\
\hline C. querceti (Gyllenhal, 1813)* & & & & & + \\
\hline C. sophiae Gyllenhal, 1837 & & + & + & & \\
\hline C. hampei C. N. F. Brisout de Barneville, 1869 & & + & + & & \\
\hline C. typhae (Herbst, 1795) & & + & & & + \\
\hline C. sp. pr. typhae (Herbst, 1795)* & & + & & & + \\
\hline C. piceolatus (C. N. F. Brisout de Barneville, 1883)* & & + & & & + \\
\hline C. rhenanus Schultze, $1895^{*}$ & & + & & & \\
\hline C. arnoldii (Korotyaev, 1980)* & & & + & & \\
\hline C. chalybaeus Germar, $1823^{*}$ & & & & & + \\
\hline C. contractus (Marsham, 1802) & & + & & & + \\
\hline C. sulcatus C. N. F. Brisout de Barneville, 1869* & & + & & & \\
\hline C. viridanus Gyllenhal, 1837 & & & + & & \\
\hline C. ignitus Germar, $1823^{*}$ & & + & & & \\
\hline C. pervicax Weise, $1883^{*}$ & & & & & + \\
\hline C. scapularis Gyllenhal, $1837^{*}$ & & & & & + \\
\hline C. barbareae Suffrian, $1847 *$ & & + & & & + \\
\hline Oprohinus consputus (Germar, 1823) & & & + & & \\
\hline O. jakovlevi (Schultze, 1902)* & & + & + & & \\
\hline Sirocalodes depressicollis (Gyllenhal, 1813)* & & & + & & \\
\hline S. quercicola (Paykull, 1792)* & + & & & & \\
\hline Glocianus distinctus (C. N. F. Brisout de Barneville, 1870)* & & + & & + & \\
\hline Mogulones pallidicornis (Gougelet \& H. Brisout de Barneville, 1860)* & + & & & & \\
\hline M. asperifoliarum (Gyllenhal, 1813)* & + & & & & \\
\hline M. austriacus (C. N. F. Brisout de Barneville, 1869) & & + & + & & \\
\hline M. crucifer (Pallas, 1771) & & + & & & \\
\hline M. dimidiatus (Frivaldszky, 1865) & & + & & & \\
\hline M. cynoglossi (Frauenfeld, 1866) & & + & & & \\
\hline Nedyus quadrimaculatus (Linnaeus, 1758) & + & & & & + \\
\hline Datonychus arquata (Herbst, 1795) & & & & & + \\
\hline Microplontus edentulus (Schultze, 1897)* & & + & & & \\
\hline M. rugulosus (Herbst, 1795)* & & & & & + \\
\hline M. triangulum (Boheman, 1845) & & + & & & + \\
\hline Thamiocolus viduatus (Gyllenhal, 1813)* & & & & & + \\
\hline Th. virgatus (Gyllenhal, 1837) & & + & + & & + \\
\hline Th. nubeculosus (Gyllenhal, 1837) & & + & + & & \\
\hline Th. sahlbergi (C. R. Sahlberg, 1845) & & + & & & + \\
\hline Zacladus geranii (Paykull, 1800) & + & + & & & + \\
\hline Coeliodinus phrymos Alonso-Zarazaga \& Colonnelli, 2017* & + & & & & \\
\hline Auleutes epilobii (Paykull, 1800)* & + & & & & \\
\hline Orobitis cyanea (Linnaeus, 1758)* & + & & & & \\
\hline
\end{tabular}


Продолжение таблицы

Continuation of Table

\begin{tabular}{|c|c|c|c|c|c|}
\hline 1 & 2 & 3 & 4 & 5 & 6 \\
\hline \multicolumn{6}{|l|}{ Подсем. Curculioninae } \\
\hline Acalyptus sericeus Gyllenhal, 1835* & & & & & + \\
\hline Acentrus histrio (Schoenherr, 1837) & & & + & & \\
\hline Ellescus scanicus (Paykull, 1792)* & & & & & + \\
\hline E. infirmus (Herbst, 1795)* & & & & & + \\
\hline Dorytomus longimanus (Forster, 1771) & & & & & + \\
\hline D. tortix (Linnaeus, 1760)* & + & & & & \\
\hline D. nordenskioldi Faust, 1883 & & & & & + \\
\hline D. taeniatus (Fabricius, 1781) & & & & & + \\
\hline D. suratus (Gyllenhal, 1835) & & & & & + \\
\hline D. nebulosus (Gyllenhal, 1835) & & & & & + \\
\hline D. rufatus (Bedel, 1888)* & & & & & + \\
\hline Anthonomus germanicus Dieckmann,1968 & & + & & & \\
\hline A. pomorum (Linnaeus, 1758) & + & & & + & \\
\hline A. incurvus (Panzer, 1795)* & + & & & + & + \\
\hline A. rufus Gyllenhal, $1835^{*}$ & & & & + & \\
\hline A. sorbi Germar, 1821* & + & & & & \\
\hline A. rubi (Herbst, 1795) & + & + & & + & + \\
\hline A. rectirostris (Linnaeus, 1758) & + & & & & + \\
\hline Curculio venosus (Gravenhorst, 1807) & + & & & & \\
\hline C. glandium Marsham, 1802 & + & & & & \\
\hline Archarius pyrrhoceras (Marsham, 1802) & + & & & & \\
\hline A. salicivorus (Paykull, 1792)* & & & & & + \\
\hline Cionus tuberculosus (Scopoli, 1763) & + & & & & + \\
\hline C. scrophulariae (Linnaeus, 1758) & + & & & & + \\
\hline C. hortulanus (Geoffroy, 1785) & & + & & + & + \\
\hline C. thapsus (Fabricius, 1792) & & + & + & & \\
\hline C. olivieri Rosenschoeld, 1838 & & + & + & + & \\
\hline Rhynchaenus xylostei Clairville, $1798^{*}$ & + & & & & + \\
\hline Tachyerges salicis (Linnaeus, 1758) & + & & & & + \\
\hline T. pseudostigma (Tempère, 1982)* & & & & & + \\
\hline Isochnus angustifrons (West, 1917)* & & & & & + \\
\hline Orchestes hortorum (Fabricius, 1792) & + & & & & \\
\hline O. rusci (Herbst, 1795)* & + & & & & \\
\hline O. testaceus (O. F. Müller, 1776)* & & & & & + \\
\hline Pseudorchestes smreczynskii (Dieckmann, 1958)* & & + & & & \\
\hline P. pratensis (Germar, 1821)* & & + & & & \\
\hline Pseudorchestes sp. & & & + & & \\
\hline Rhamphus oxyacanthae (Marsham, 1802) & & & & + & \\
\hline Rh. pulicarius (Herbst, 1795)* & & & & & + \\
\hline Mecinus janthinus Germar, 1821 & & + & & & \\
\hline M. plantaginis (Eppelsheim, 1875) & & + & + & & \\
\hline Gymnetron terminassianae Smreczyński, 1975 & & & & & + \\
\hline G. melanarium (Germar, 1821) & & + & & & + \\
\hline G. villosulum Gyllenhal, 1838* & & & & & + \\
\hline Rhinusa tetra (Fabricius, 1792) & & + & + & + & \\
\hline Rh. neta (Germar, 1821) & & + & & & + \\
\hline Rh. antirrhini (Paykull, 1800) & & + & & & + \\
\hline Rh. collina (Gyllenhal, 1813) & & + & & & \\
\hline Rh. linariae (Panzer, 1795) & & + & & & \\
\hline Miarus monticola Petri, $1912^{*}$ & & + & & & \\
\hline
\end{tabular}


Продолжение таблицы

Continuation of Table

M. ajugae (Herbst, 1795)

Cleopomiarus graminis (Gyllenhal, 1813)

Pachytychius sparsutus (Olivier, 1807)

Smicronyx coecus (Reich, 1797)*

S. jungermanniae (Reich, 1797)

S. nebulosus Tournier, 1874

Tychius quinquepunctatus (Linnaeus, 1758)

T. uralensis Pic, 1902

T. meliloti Stephens, 1831

T. breviusculus Desbrochers des Loges, 1873

T. medicaginis C. N. F. Brisout de Barneville, 1863

T. sharpi Tournier, 1874

T. stephensi Schoenherr, 1835

T. flavus Becker, 1864*

T. picirostris (Fabricius, 1787)

Sibinia subelliptica Desbrochers des Loges, 1873

S. pellucens (Scopoli, 1772)

S. viscariae (Linnaeus, 1760)

S. tibialis Gyllenhal, 1835

S. vittata Germar, 1823

S. hopffgarteni Tournier, 1874

Pseudostyphlus pillumus (Gyllenhal, 1835)*

Bagous validus Rosenhauer, 1847* Подсем. Bagoinae

Metadonus anceps (Boheman, 1842)

H. conmaculata (Herbst, 1795)

H. meles (Fabricius, 1792)

H. viciae (Gyllenhal, 1813)*

H. miles (Paykull, 1792)

Подсем. Entiminae

Otiorhynchus velutinus Germar, 1823

O. ovatus (Linnaeus, 1758)

O. chrysostictus Gyllenhal, 1834

O. ligustici (Linnaeus, 1758)

O. politus Gyllenhal, 1834*

O. concinnus Gyllenhal, 1834

O. unctuosus Germar, 1823

Trachyphloeus spinimanus Germar, 1823

Sphaeroptochus fasciolatus (Gebler, 1829)

Omias puberulus Boheman, 1834

O. verruca Boheman, 1834

O. murinus (Boheman, 1842)

Phyllobius viridicollis (Fabricius, 1792)

Ph. brevis Gyllenhal, 1834

Ph. oblongus (Linnaeus, 1758)

Ph. pyri (Linnaeus, 1758)

Ph. pomaceus Gyllenhal, 1834

Ph. jacobsoni Smirnov, 1913

Ph. contemptus Schoenherr, 1832

\begin{tabular}{|c|c|c|c|c|}
\hline 2 & 3 & 4 & 5 & 6 \\
\hline \multirow[t]{6}{*}{+} & + & & & \\
\hline & + & + & & \\
\hline & & & + & \\
\hline & & & & + \\
\hline & + & + & & \\
\hline & & + & & \\
\hline \multirow[t]{10}{*}{+} & + & + & + & + \\
\hline & & + & + & \\
\hline & + & + & & + \\
\hline & + & + & & + \\
\hline & + & + & & \\
\hline & + & & & \\
\hline & + & & & + \\
\hline & & + & & \\
\hline & + & & . & + \\
\hline & + & + & + & \\
\hline \multirow[t]{9}{*}{+} & + & + & + & + \\
\hline & + & + & + & \\
\hline & + & & & \\
\hline & & + & & \\
\hline & + & + & + & \\
\hline & + & & & + \\
\hline & & & & + \\
\hline & & & & \\
\hline & & + & & \\
\hline \multirow[t]{2}{*}{+} & & & & + \\
\hline & & & & + \\
\hline \multirow[t]{4}{*}{+} & & & + & \\
\hline & + & & & + \\
\hline & & & & \\
\hline & + & & & \\
\hline \multirow[t]{2}{*}{+} & + & & & + \\
\hline & + & & + & \\
\hline \multirow[t]{9}{*}{+} & & & & + \\
\hline & & & & + \\
\hline & & & + & \\
\hline & + & + & + & \\
\hline & + & & & \\
\hline & & + & + & \\
\hline & + & & & \\
\hline & + & & & \\
\hline & & & & + \\
\hline+ & & & + & + \\
\hline \multirow[t]{2}{*}{+} & + & + & + & + \\
\hline & & & + & + \\
\hline+ & & & + & + \\
\hline \multirow{3}{*}{+} & & & & + \\
\hline & & & & + \\
\hline & + & & + & + \\
\hline
\end{tabular}


Окончание таблицы End of Table

\begin{tabular}{|c|c|c|c|c|c|}
\hline 1 & 2 & 3 & 4 & 5 & 6 \\
\hline Ph. crassipes Motschulsky, 1860 & & & & & + \\
\hline Ph. maculicornis Germar, 1823 & + & & & + & + \\
\hline Ph. argentatus (Linnaeus, 1758) & + & & & & + \\
\hline Polydrusus pterygomalis Boheman, 1840* & + & & & & \\
\hline P. cervinus (Linnaeus, 1758) & + & & & & \\
\hline P. inustus Germar, 1823 & + & + & & + & \\
\hline P. tereticollis (De Geer, 1775) & + & & & + & + \\
\hline P. mollis (Strøm, 1768) & + & & & & + \\
\hline Foucartia squamulata (Herbst, 1795) & & + & & & \\
\hline Sciaphobus ningnidus (Germar, 1823) & & & & & + \\
\hline Sciaphilus asperatus (Bonsdorff, 1785) & + & & & & + \\
\hline Eusomus ovulum Germar, 1823 & & + & & + & + \\
\hline Eusomostrophus acuminatus (Boheman, 1840) & & + & + & & \\
\hline Tanymecus palliatus (Fabricius, 1787) & & + & & & + \\
\hline Sitona macularius (Marsham, 1802) & & + & + & + & + \\
\hline S. lineellus (Bonsdorff, 1785) & & & & & + \\
\hline S. languidus Gyllenhal, 1834 & & + & & + & \\
\hline S. striatellus Gyllenhal, 1834 & + & & + & + & + \\
\hline S. ambiguus Gyllenhal, 1834 & + & + & & & \\
\hline S. inops Schoenherr, 1832 & & + & & + & + \\
\hline S. sulcifrons (Thunberg, 1798) & & + & & + & + \\
\hline S. lineatus (Linnaeus, 1758) & & + & & & + \\
\hline S. lateralis Gyllenhal, 1834 & + & + & & & + \\
\hline S. suturalis Stephens, 1831 & & + & & & + \\
\hline S. cylindricollis Fåhraeus, 1840 & & + & + & & + \\
\hline S. obsoletus (Gmelin, 1790) & & + & & & + \\
\hline Всего: & 86 & 134 & 71 & 49 & 143 \\
\hline
\end{tabular}

Примечание: * - вид, впервые указан в публикациях для фауны Оренбургской области.

Главной особенностью фауны долгоносиков в зоогеографическом отношении является контрастное сочетание группировок видов разного происхождения, часто находящихся на границах (или вблизи границ) своего распространения. С одной стороны, это западнопалеарктические неморальные виды, тесно связанные с европейскими широколиственными лесами. В первую очередь к ним относится комплекс видов, развивающихся на дубе. Помимо пяти видов, указанных ранее (Attelabus nitens (рис. 6Б), Curculio glandium, Curculio venosus, Archarius pyrrhoceras, Orchestes hortorum] [Дедюхин, 2019б], это ксилофаг Gasterocercus depressirostris (F.). Эта же группировка (за исключением последнего вида) была отмечена нами в Предуралье и Южном Урале в пределах Башкирии [Дедюхин, 2016в; Дедюхин, Мартыненко, 2020]. Таким образом, можно констатировать, что вплоть до восточного предела своего распространения консорция дуба на Южном Урале включает обширную группу его монофагов, что опровергает представление о практическом отсутствии на горном Урале специфической дубовой фауны жуков-долгоносиков [Легалов и др., 2006, 2007]. В Шайтан-Тау отмечены и два неморальных вида, связанные с вязами (Ulmus). Это довольно обычный для данной консорции - Magdalis armigera и впервые обнаруженный на Урале западнопалеарктический вид Magdalis caucasica ${ }^{2}$. Вид широко, но спорадично

${ }^{2}$ Материал: Оренбургская обл., Кувандыкский р-н., окр. дер. М. Чураево, хр. Шайтантау, 26-28.V. 2010, А.М. Шаповалов; 2 экз. 
распространен в странах Восточной и Центральной Европы, на север до Польши и Латвии, в Турции и на Кавказе [Mazur et al., 2014]. Самые северо-восточные находки вида были известны из Предкавказья (Краснодарский и Ставропольский края) [Барриос, 1986]. Таким образом, популяция вида в Шайтан-Тау, безусловно, имеет реликтовый характер. Показательно также обнаружение здесь видов долгоносиков, тесно связанных с неморальными видами травянистых растений: Ceutorhynchus roberti (на Alliaria petiolata), и C. interjectus (на Sisymbrium strictissimum) и C. inaffectatus (на Hesperis sp.). Из них первые два в Шайтан-Тау находятся на восточных границах своих ареалов, а C. inaffectatus coбран первым автором и в среднегорье Центрального Алтая. Самое восточное местонахождение здесь отмечено и для трубковерта Mecorhis ungarica, связанного с шиповниками (на Шайтан-Тау вид живет на Rosa glabrifolia) (рис. 6А).

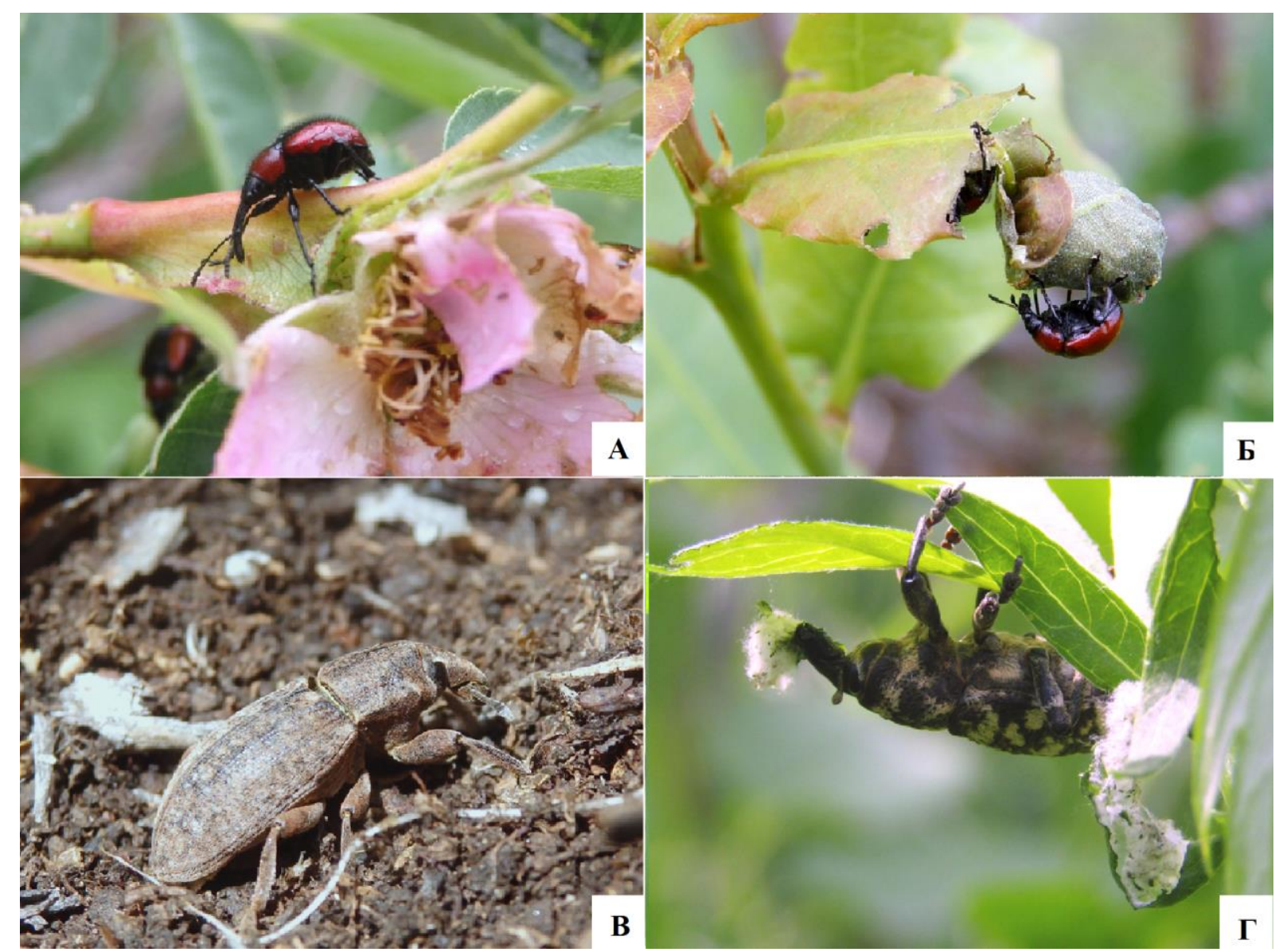

Рис. 6. Некоторые виды жуков на территории заповедника «Шайтан-Тау», находящиеся на границах распространения: А - Mecorhis ungarica (Hbst.); Б - Attelabus nitens (Scop.); $\mathrm{B}-$ Pseudocleonus dauricus (Gebl.); $\Gamma$-Adosomus roridus (Pall.)

Fig. 6. Some species of weevils located on the borders of distribution on the territory of the Shaitan-Tau reserve: A - Mecorhis ungarica (Hbst.); Б - Attelabus nitens (Scop.); B - Pseudocleonus dauricus (Gebl.); $\Gamma$-Adosomus roridus (Pall.)

С другой стороны, в лесах и особенно в тенистых уремах поймы Сакмары здесь отмечен и ряд бореальных и даже арктобореальных видов, не идущих далее на юг (Magdalis carbonaria, Rutidosoma graminosus, Ceutorhynchus querceti, Auleutes epilobii, Dorytomus nordenskioldi, Tachyerges pseudostigma, Otiorhynchus politus, Phyllobius jacobsoni).

Довольно обширен и неоднороден степной комплекс (около 70 видов). С одной стороны, здесь преобладают виды, характерные для луговых степей лесостепной зоны (Aspidapion soror, Squamapion samarense, Exapion difficile, E. corniculatum, Protapion 
ruficrus, Larinus serratulae, Malvaevora timida, Thamiocolus virgatus, Mecinus plantaginis, Tychius sharpi, Sibinia subelliptica, S. hopffgarteni, Otiorhynchus chrysostictus, Sitona languidus), с другой, - присутствует значительное число южностепных ксерофилов, не характерных для зональных сообществ лесостепи и концентрирующиеся в основном на петрофитностепных склонах сопок (Diplapion sareptanum, Adosomus roridus (рис. 6Г), Larinus centaurii, Lixus scolopax, Ceutorhynchus fabrilis, Oprohinus consputus, Acentrus histrio, Sibinia vittata). Отдельно выделятся группа степных и горно-степных видов восточного происхождения (Pseudocleonus dauricus (рис. 6B), Ceutorhynchus kaszabi, Oprohinus jakovlevi, Tychius uralensis, Sphaeroptochus fasciolatus), обитающих в каменистых и кустарниковых степях.

Анализ распределения видового богатства по основным типам биотопов (см. таблицу) показывает, что наиболее разнообразные комплексы долгоносиков сосредоточены, с одной стороны, в мезо-ксерофитных и мезофитных травянистых биотопах (остепненные луга, опушки и злаково-разнотравные степи), с другой, - в пойме p. Сакмары (прибрежная растительность, включая осокорники и ивняки, а также заболоченные берега стариц). Довольно специфичный, хотя и не очень богатый комплекс, представлен в сообществах зарослей степных кустарников, местами сплошь покрывающих склоны сопок. Значительное число видов отмечено также в водораздельных широколиственных лесах и в петрофитных горных степях. Правда, разнообразие долгоносиков в последних заметно ниже, чем в равнинных каменистых степях, формирующихся на останцах с органогенным известняковым или меловым субстратом [Дедюхин, 2015, 2016б; 2020]. Это, вероятно, обусловлено более жесткими условиями, связанными с особенностями горных пород, препятствующими в частности, успешной перезимовке видов; при этом отсутствие на Шайтан-Тау крупных выходов известняков заметно обедняет здесь петрофитностепную флору за счет отсутствия в ней кальцефитных видов растений. А именно в основном с кальцефитами связан богатый и специфичный комплекс жуков-долгоносиков каменистых степей.

Таким образом, общий очень высокий уровень видового богатства фауны долгоносиков Шайтан-Тау обусловлен не столько высоким уровнем разнообразия этой группы в отдельных биотопах, сколько контрастным сочетанием комплексов, а именно дубравной лесостепи и петрофитных степей в горной части заповедника и развитой поймой р. Сакмары.

\section{Заключение}

В результате исследований было выявлено 288 видов долгоносикообразных жуков из 6 семейств. Из них 79 видов впервые указываются для фауны Оренбургской области. Локальную фауну заповедника отличают неоднородная зоогеографическая структура и контрастное сочетание низкогорных лесостепных, петрофитностепных и пойменных комплексов, каждый из которых отличается высоким видовым богатством и содержит группы видов (неморальных, бореальных, степных), находящихся здесь на маргинальных частях своих ареалов. Данные, представленные в статье, подтверждают обоснованность проведения по хребту Шайтан-Тау ряда биогеографических границ и подчеркивают важное значение заповедника для сохранения своеобразных природных комплексов Уральской горной страны.

\section{Благодарности}

Авторы признательны А.М. Шаповалову (г. Санкт-Петербург) и С.Ю. Есюнину (Пермский государственный национальный исследовательский университет, Пермь) за предоставление сборов жуков-долгоносиков; Б.А. Короятеву (Зоологический институт РАН, г. Санкт-Петербург) за помощьв в определении некоторых видов жуковдолгоносиков. 


\section{Список литературы}

1. Барриос Э.Э. 1986. Обзор рода Magdalis Germar (Coleoptera, Curculionidae) фауны Европейской части СССР и Кавказа. Энтомологическое обозрение, 65 (2): 382-402.

2. Бей-Биенко Г.Я. (ред.). 1965. Определитель насекомых европейской части СССР. Т. 2. Жесткокрылые и веерокрылые. М., Л., Наука, 668 с.

3. Дедюхин С.В. 2015. Разнообразие растительноядных жуков (Coleoptera: Chrysomeloidea, Curculionoidea) в степных сообществах лесостепи Высокого Заволжья. Энтомологическое обозрение, 94 (3): 626-650.

4. Дедюхин С.В. 2016а. Зональная дифференциация фауны растительноядных жуков (Coleoptera: Chrysomeloidea, Curculionoidea) на востоке Русской равнины. Евразиатский энтомологический журнал, 15 (2): 164-182.

5. Дедюхин С.В. 2016б. Видовое богатство и зональные особенности парциальных фаун жуков-фитофагов (Coleoptera, Chrysomeloidea, Curculionoidea) травянистых склонов на востоке Русской равнины и в Предуралье. Зоологический журнал, 95 (9): 1053-1065.

6. Дедюхин С.В. 2016в. Новые данные о составе растительноядных жуков (Coleoptera: Attelabidae, Chrysomelidae, Curculionidae), связанных с дубом (Quercus robur L.), в Предуралье и на Южном Урале. $B$ кн.: Природа, наука и туризм. Сборник материалов всероссийской научнопрактической конференции, посвященной 30-летию национального парка «Башкирия». Уфа, Гилем: $145-152$.

7. Дедюхин С.В. 2019а. К инвентаризации фауны жуков-листоедов (Coleoptera, Chrysomelidae) заповедников Оренбуржья. В кн.: Труды ФГБУ «Заповедники Оренбуржья». Вып. II. Заповедники Оренбуржья в природоохранном каркасе России. Оренбург-Саратов, ООО «Амирит»: 119-131.

8. Дедюхин С.В. 2019б. Предварительные результаты изучения растительноядных жесткокрылых (Coleoptera, Chrysomelidae и Curculionoidea) в заповедниках Оренбуржья и перспективы дальнейших исследований. Bопросы степеведения, 15: 91-94.

9. Дедюхин С.В. 2020. Особенности фауны и сообществ растительноядных жуков (Coleoptera: Chrysomeloidea, Curculionoidea) шиханов близ г. Стерлитамак (Республика Башкортостан). Зоологический журнал, 99 (4): 413-421.

10. Дедюхин С.В., Мартыненко В.Б. 2020. Консортивные связи жуков-фитофагов (Coleoptera: Chrysomeloidea и Curculionoidea) с растениями на уникальных Стерлитамакских шиханах. Энтомологическое обозрение, 99 (2): 339-367. DOI: 10.31857/S0367144520020100

11. Забалуев И.А. 2020. Определитель жуков-долгоносиков (Coleoptera: Curculionidae) России. URL: http://coleop123.narod.ru/key/opredslon/opred_slon.html (дата обращения: 20 марта 2020).

12. Зоны и типы поясности растительности России и сопредельных территорий (1:8000000). Под ред. Г.Н. Огуреевой. Москва, 1999. Карта на 2 л.

13. Исаев А.Ю. 2007. Определитель жесткокрылых Среднего Поволжья. Ч. 3. PolyphagaPhytophaga. Ульяновск, Вектор-С, 256 с.

14. Калмыкова О.Г., Вельмовский П.В., Барбазюк Е.В., Кин И.О. 2016. К вопросу об эффективности сохранения экосистем заповедника «Шайтан-Тау» в его современных границах. Известия Иркутского государственного университета. Серия «Биология. Экология», 18: 99-105.

15. Кин И.О., Барбазюк Е.В., Калмыкова О.Г. 2016 Роль заповедника «Шайтан-Тау» в сохранении редких представителей флоры и фауны Оренбургской области. Известия Самарского научного иентра Российской академии наук, 18 (5(2)): 296-300.

16. Легалов А.А., Шевнин Е.Ю., Легалова С.Е. 2006. Особенности распространения жуковтрубковертов и долгоносиков (Coleoptera, Attelabidae, Curculionidae), связанных с дубом черешчатым (Quercus robur L.) на восточной границе его ареала. В кн.: Изучение заповедной природы Южного Урала. Сборник научных трудов. Уфа: 244-248.

17. Легалов А.А., Пойрас А.А., Легалова С.Е., Шевнин Е.Ю. 2007.Особенности фауны долгоносикообразных жуков, связанных с дубом, в Южном Предуралье. Алтайский зоологический журнал, 1: 37-38.

18. Мулдашев А.А., Галеева А.Х. 1994. Флора хребта Шайтан-Тау. В кн.: Дубравная лесостепь на хребте Шайтан-Тау и вопросы ее охраны. Уфа, Уфимский научный центр РАН: C. $17-27$. 
19. Романова Ю.П. 2011. Флористические особенности проектируемого лесостепного заповедника «Шайтан-Тау». Вопросы степеведения, 9: 127-131.

20. Чибилев А.А. 2015. Заповедник «Шайтан-Тау» - эталон дубравной лесостепи на Южном Урале. Оренбург, Печатный дом «Димур», 144 с.

21. Шаповалов А.M. 2011. Материалы к фауне жуков-усачей (Coleoptera, Cerambycidae) проектируемого заповедника «Шайтантау» (Оренбургская область). Tруды Оренбургского отделения РЭО, 1: 100-116.

22. Шаповалов А.М. 2012. Жуки-усачи Оренбургской области: фауна, распространение, биономия. Труды Оренбургского отделения РЭО, 3: 1-224.

23. Шаповалов А.М., Григорьев В.Е., Немков В.А., Русаков А.В., Казаков Е.П. 2011. Интересные находки жесткокрылых (Coleoptera) в Оренбургской области. Труды Оренбургского отделения РЭО. 1: 39-48.

24. Alonso-Zarazaga M.A., Barrios H., Borovec R., Caldara R., Colonnelli E., Gültekin L., Hlaváč P., Korotyaev B., Lyal C.H.C., Machado A., Meregalli M., Pierotti H., Ren L., Sánchez-Ruiz M., Sforzi A., Silfverberg H., Skuhrovec J., Trýzna M., Velázquez de Castro A.J., Yunakov N.N. 2020. Cooperative Catalogue of Palaearctic Coleoptera Curculionoidea. Part 1: Introduction and Catalogue. Work Version 2.5 Available at: http://weevil.info/content/palaearctic-catalogue

25. Dieckmann L. 1972. Beiträge zur Insektenfauna der DDR: Coleoptera - Curculionidae: Ceutorhynchinae. Beiträge zur Entomologie, 22 (1-2): 3-128. (in German)

26. Dieckmann L. 1974. Beiträge zur Insektenfauna der DDR: Coleoptera - Curculionidae (Rhinomacerinae, Rhynchitinae, Attelabinae, Apoderinae). Beiträge zur Entomologie, 24 (1/4): 5-54. (in German)

27. Dieckmann L. 1977. Beiträge zur Insektenfauna der DDR: Coleoptera - Curculionidae: Apioninae. Beiträge zur Entomologie, 27 (1): 7-143. (in German)

28. Dieckmann L. 1983. Beiträge zur Insektenfauna der DDR: Coleoptera - Curculionidae (Tanymecinae, Leptopiinae, Cleoninae, Tanyrhinchinae, Cossoninae, Raymondionyminae, Bagoinae, Tanysphyrinae. Beiträge zur Entomologie, 33 (2): 257-381. (in German)

29. Dieckmann L. 1988. Beiträge zur Insektenfauna der DDR: Coleoptera - Curculionidae (Curculioninae: Ellescini, Acalyptini, Tychiini, Anthonomini, Curculionini). Beiträge zur Entomologie, 38 (2): 365-468. (in German)

30. Mazur M., Olbrycht T., Szewkienicz A. 2014. Magdalis (Odontomagdalis) caucasica (Tournier, 1872) (Coleoptera: Curculionidae) - A first record in Poland and summary data on the occurrence in Europe. Baltic Journal of Coleopterology, 14 (1): 53-58.

\section{References}

1. Barrios E.E. 1986. Review of the genus Magdalis Germar (Coleoptera, Curculionidae) of the fauna of the European part of the USSR and the Caucasus. Entomological Review, 65 (2): 382-402. (in Russian)

2. Bey-Bienko G.Ya. (eds.). 1965. Opredelitel' nasekomykh evropeyskoy chasti SSSR. T. 2. Zhestkokrylyye i veyerokrylyye [Key to insects of the European part of the USSR. Vol. 2. Beetles and winged insects]. Moscow, Leningrad, Nauka, 668 p.

3. Dedyukhin S.V. 2015. Diversity of phytophagous beetles (Coleoptera: Chrysomeloidea, Curculionoidea) in the steppe communities of the forest-steppe of the High Trans-Volga region. Entomological Review, 94 (3): 626-650. (in Russian)

4. Dedyukhin S.V. 2016a. Zonal differentiation of the fauna of phytophagous beetles (Coleoptera: Chrysomeloidea, Curculionoidea) in the East of the Russian Plain. Eurasian Entomological Journal, 15 (2): 164-182. (in Russian)

5. Dedyukhin S.V. 20166. Species richness and zonal features of the partial faunas of phytophagous beetles (Coleoptera, Chrysomeloidea, Curculionoidea) of herbaceous slopes in the East of the Russian Plain and in the Urals. Zoological Journal, 95 (9): 1053-1065. (in Russian)

6. Dedyukhin S.V. 2016в. Novye dannye o sostave rastitel'noyadnykh zhukov (Coleoptera: Attelabidae, Chrysomelidae, Curculionidae), svyazannykh s dubom (Quercus robur L.), v Predural'ye i na Yuzhnom Urale. [New data on the composition of phytophagous beetles (Coleoptera: Attelabidae, Chrysomelidae, Curculionidae) associated with oak (Quercus robur L.) in the Urals and Southern Urals]. In: 
Priroda, nauka i turizm [Nature, science and tourism]. Collection of materials of the All-Russian scientificpractical conference dedicated to the 30th anniversary of the Bashkiria National Park. Ufa, Gilem: 145-152.

7. Dedyukhin S.V. 2019a. K inventarizatsii fauny zhukov-listoyedov (Coleoptera, Chrysomelidae) zapovednikov Orenburzh'ya [To an inventory of the fauna of leaf beetles (Coleoptera, Chrysomelidae) in the reserves of the Orenburg region]. In: Trudy FGBU «Zapovedniki Orenburzh'ya». Vyp. II. Zapovedniki Orenburzh'ya v prirodookhrannom karkase Rossii [Proceedings of the Federal State Budgetary Institution "Nature reserves of the Orenburg region". Vol. II. Nature reserves of the Orenburg region in the nature protection framework of Russia.]. Orenburg-Saratov, OOO "Amirit": 119-131.

8. Dedyukhin S.V. 2019b. Preliminary results of studying phytophagous beetles (Coleoptera, Chrysomelidae and Curculionoidea) in the reserves of the Orenburg region and prospects for further research. Questions of Steppe Studies, 15: 91-94. (in Russian)

9. Dedyukhin S.V. 2020. Features of the fauna and communities of phytophagous beetles (Coleoptera: Chrysomeloidea, Curculionoidea) shikhans near Sterlitamak (Republic of Bashkortostan). Zoological Journal, 99 (4): 413-421. (in Russian)

10. Dedyukhin S.V., Martynenko V.B. 2020. Consortial Associations of Phytophagous Beetles (Coleoptera: Chrysomeloidea, Curculionoidea) with Plants on the Unique Sterlitamak Shikhans. Entomological Review, 99 (2): 339-367. DOI: 10.31857 / S0367144520020100 (in Russian)

11. Zabaluev I.A. 2020. Key to weevils (Coleoptera: Curculionidae) of Russia. Available at: http://coleop123.narod.ru/key/opredslon/opred_slon.html (accessed: 20 March 2020). (in Russian)

12. Zones and types of vegetation zonation in Russia and adjacent territories (1:8000000). Ed. G.N. Ogureeva. Moscow, 1999, map on 2 p. (in Russian)

13. Isaev A. Yu. 2007. Opredelitel' zhestkokrylykh Srednego Povolzh'ya. Ch. 3. PolyphagaPhytophaga [Keys to Coleoptera of the Middle Volga Region. Part 3. Polyphaga - Phytophaga]. Ulyanovsk, Vector-S, $256 \mathrm{p}$.

14. Kalmykova O.G., Velmovskiy P.V., Barbazyuk E.V., Kin I.O. 2016. On the issue of the effectiveness of the conservation of ecosystems of the "Shaitan-Tau" reserve within its modern boundaries. Irkutsk State University Bulletin. Series “Biology. Ecology”, 18: 99-105. (in Russian)

15. Kin I.O., Barbazyuk E.V., Kalmykova O.G. 2016 The role of the Shaitan-Tau reserve in the preservation of rare representatives of flora and fauna of the Orenburg region. Izvestia of the Samara Scientific Center of the Russian Academy of Sciences, 18 (5(2)): 296-300. (in Russian)

16. Legalov A.A., Shevnin E.Yu., Legalova S.E. 2006. Osobennosti rasprostraneniya zhukovtrubkovertov i dolgonosikov (Coleoptera, Attelabidae, Curculionidae), svyazannykh s dubom chereshchatym (Quercus robur L.) na vostochnoy granitse yego areala [Peculiarities of distribution of pipe-weevils and weevils (Coleoptera, Attelabidae, Curculionidae) associated with pedunculate oak (Quercus robur L.) on the eastern border of its range]. In: Izucheniye zapovednoy prirody Yuzhnogo Urala [Study of the reserved nature of the Southern Urals]. Collection of scientifical works. Ufa: 244-248.

17. Legalov A.A., Poyras A.A., Legalova S.E., Shevnin E.Yu. 2007. Features of the fauna of weevils associated with oak in the southern Urals. Altai Zoological Journal, 1: 37-38. (in Russian)

18. Muldashev A.A., Galeeva A.Kh. 1994. Flora khrebta Shaytan-Tau [Flora of the Shaitan-Tau ridge]. In: Dubravnaya lesostep' na khrebte Shaytan-Tau i voprosy yeye okhrany [Oak forest-steppe on the Shaitan-Tau ridge and issues of its protection]. Ufa, Ufa Scientific Center RAS: 17-27.

19. Romanova Yu.P. 2011. Floristic features of the projected forest-steppe reserve "Shaitan-Tau". Questions of Steppe Studies, 9: 127-131. (in Russian)

20. Chibilev A.A. 2015. Zapovednik "Shaytan-Tau" - etalon dubravnoy lesostepi na Yuzhnom Urale [The "Shaitan-Tau" reserve is a model of the oak forest-steppe in the Southern Urals]. Orenburg, Printing house "Dimur", $144 \mathrm{p}$.

21. Shapovalov A.M. 2011. Materialy k faune zhukov-usachey (Coleoptera, Cerambycidae) proyektiruyemogo zapovednika "Shaytantau" (Orenburgskaya oblast') [Materials for the fauna of longhorn beetles (Coleoptera, Cerambycidae) of the projected reserve "Shaitantau" (Orenburg region)]. Trudy Orenburgskogo otdeleniya REO, 1: 100-116.

22. Shapovalov A.M. 2012. Zhuki-usachi Orenburgskoy oblasti: fauna, rasprostraneniye, bionomiya [Longhorn beetles of the Orenburg region: fauna, distribution, bionomy]. Trudy Orenburgskogo otdeleniya REO, 3: 1-224.

23. Shapovalov A.M., Grigoriev V.E., Nemkov V.A., Rusakov A.V., Kazakov E.P. 2011. Interesnyye nakhodki zhestkokrylykh (Coleoptera) v Orenburgskoy oblasti [Interesting findings of coleoptera (Coleoptera) in the Orenburg region]. Trudy Orenburgskogo otdeleniya REO, 1: 39-48. 
24. Alonso-Zarazaga M.A., Barrios H., Borovec R., Caldara R., Colonnelli E., Gültekin L., Hlaváč P., Korotyaev B., Lyal C.H.C., Machado A., Meregalli M., Pierotti H., Ren L., Sánchez-Ruiz M., Sforzi A., Silfverberg H., Skuhrovec J., Trýzna M., Velázquez de Castro A.J., Yunakov N.N. 2020. Cooperative Catalogue of Palaearctic Coleoptera Curculionoidea. Part 1: Introduction and Catalogue. Work Version 2.5 Available at: http://weevil.info/content/palaearctic-catalogue

25. Dieckmann L. 1972. Beiträge zur Insektenfauna der DDR: Coleoptera - Curculionidae: Ceutorhynchinae. Beiträge zur Entomologie, 22 (1-2): 3-128. (in German)

26. Dieckmann L. 1974. Beiträge zur Insektenfauna der DDR: Coleoptera - Curculionidae (Rhinomacerinae, Rhynchitinae, Attelabinae, Apoderinae). Beiträge zur Entomologie, 24 (1/4): 5-54. (in German)

27. Dieckmann L. 1977. Beiträge zur Insektenfauna der DDR: Coleoptera - Curculionidae: Apioninae. Beiträge zur Entomologie, 27 (1): 7-143. (in German)

28. Dieckmann L. 1983. Beiträge zur Insektenfauna der DDR: Coleoptera - Curculionidae (Tanymecinae, Leptopiinae, Cleoninae, Tanyrhinchinae, Cossoninae, Raymondionyminae, Bagoinae, Tanysphyrinae. Beiträge zur Entomologie, 33 (2): 257-381. (in German)

29. Dieckmann L. 1988. Beiträge zur Insektenfauna der DDR: Coleoptera - Curculionidae (Curculioninae: Ellescini, Acalyptini, Tychiini, Anthonomini, Curculionini). Beiträge zur Entomologie, 38 (2): 365-468. (in German)

30. Mazur M., Olbrycht T., Szewkienicz A. 2014. Magdalis (Odontomagdalis) caucasica (Tournier, 1872) (Coleoptera: Curculionidae) - A first record in Poland and summary data on the occurrence in Europe. Baltic Journal of Coleopterology, 14 (1): 53-58.

Поступила в редакиฺию 15.09.2020

\section{Ссылка для цитирования статьи For citation}

Дедюхин С.В., Филимонов Р.В. 2020. Состав фауны и биотопическое распределение долгоносикообразных жуков (Coleoptera, Curculionoidea) заповедника Шайтан-тау. Полевой журнал биолога, 2 (3): 185-204. DOI 10.18413/2658-3453-2020-2-3-185-204

Dedyukhin S.V., Filimonov R.V. 2020. Fauna Composition and Biotopic Distribution of Weevils (Coleoptera, Curculionoidea) of the Shaytan-Tau Reserve. Field Biologist Journal, 2 (3): 185-204. DOI 10.18413/2658-3453-2020-2-3-185-204 